\title{
Multimedia role in virtual education and training via the electronic publish- ing for animation to develop the vision of Sino-Egyptian Education (2030) (An analytical study)
}

\author{
Dr.Dina Ali Mohamed El-Besomey
}

Assistant Professor, at Faculty of Applied Arts, Advertisement \& print \& Publication department, Benha University, Egypt.

DOI: 10.21608/jdsaa.2021.38204.1073

\section{Keywords:}

Multimedia ,Electronic publication, animation film, Egyptian Academic Education view.

\begin{abstract}
:
The importance of this research lies in that it deals with virtual reality as an effective way to simulate reality whatever its circumstances and difficult, through which it can be configured for different environments told the reality of an individual can't be accessed or coexistence with them.As china builds the largest nursery for engineers and scientific researchers in the world .Egypt also has a new vision to develop university education 2030. so both could develop vocational \& artificial \& technical training and they could have co- projects of virtual education process. For example. Studying sun groups and its plants can't be lived in realistic by the educated student in the university environment, and there is the role of virtual reality in composing an environment similar to this environment. This is actually modelling in Alexandria library, Alex, Egypt to enable the student to interact with it as if in the real environment .This includes the axis of education technology between reality and hope to achieve the vision of China and Egypt in 2030, which dealt with this worksheet on a set of important items, which deals with technological innovations in education technology and computer science education.
\end{abstract}




\section{1- Introduction}

Computer graphics began in the animation education industry in China in the late of seventies and expanded considerably since the last ten years. Universities across the country are using computer graphics in her programs, in addition, there are training courses for students at universities, academic training and education centers in universities in China to get a university degree in animation and provide job opportunities and training seminars for teachers of computer graphics and researchers. They usually form part of the curriculum for a more general article (usually computer science). Also, many universities offer degrees in animation, design the illustration as well as cinema techniques. which helps professional life in that area .as The labor market Participates in skills' development and vocational \& artificial \& technical training of the mechanisms of Chinese animation industry with specialized educational institutions:

The reconstruction of the Chinese university education structure was one of the most important great achievements in the era of Deng, after the disaster that hit the Cultural Revolution. In 1970, the year of the setback was found in China 48000 university student, and this number rose up in 1997 to 3.2 million, and until 2000 to 5.6 million. in the era of Mao was the "Red loyalty" rather than efficiency is the deciding factor for accepting students in the university study during the seventies, but in the time of Deng, it has been approved the method of entrance examinations .The Chinese elite universities in Beijing, such as (Beida University) in Shanghai is considered by the quality of students - and to some extent the quality and competencies of the faculty staff. As china builds the largest nursery for engineers and scientific researchers in the world.

So This research studies the role of multimedia in virtual education and training via the electronic publishing for animation to develop the vision of SinoEgyptian education (2030). This is an analytical study which draws the roadmap of developing the vision of Sino -Egyptian education (2030) - the ten years plan - via both e-learning \& e-training. It will provide a clear and succinct picture of both china and Egypt goals and strategies.

\section{2- The Research aim:}

This is an analytical study for the role of multimedia in virtual learning \& training via electronic publication of animation film to develop Chinese \& Egyptian academic education view (2030). The research deals with virtual reality as an effective way to simulate reality whatever his circumstances and difficult, through which it can be configured for different environments tell the reality of an individual can't be accessed or coexistence with them. This includes the axis of education technology between the reality and hoped to achieve the 2030 Egypt vision, which dealt with this work sheet on a set of important items, which deals with technological renewments in education technology and educational computer science.

\section{3-The importance of research:}

This research deals with the most important benefits of virtual education with both virtual learning and virtual training, where e-training and what distinguishes it from traditional education.

1- The possibility of study anywhere in the world without being restricted by geographical boundaries.

2- Having greater freedom in your studies and your business time control.

3- The adoption of the Internet as a primary source and a huge to elicit information that make students aware and informed of the latest findings of the researchers in the field of study, especially if he was studying a technical fields evolving moment by moment.

4- Virtual education reduces opportunities for young brain drain from their countries, searching of new knowledge.

5- The nature of the study default, which is primarily based on the discussion of mutual and interactive dialogue between students and teachers, make the student a major participant in the educational process, making a style with a great benefit to the student, breaking the traditional way of the default teaching which based on the fact that the student is just the recipient and the teacher is just receiver.

6- Students can study rare specialties which is hard to find in many of the world's universities.

7- This type of education doesn't require the presence of school buildings or classrooms. 
8- virtual education allow to improve the independence of persons with disabilities and rehabilitation of persons with educational deficiencies.

9- Virtual reality allows the individual to see things from long distances, and that examines the visual things as an individual can grope the different dimensions of things (3d)

10- Virtual learning creates opportunity for student participation and interaction with the program or scientific experience.

11- It also provides an appropriating opportunity for students to interact with scientific experience during the open time period and not specific.

12- It also salutes the interaction between the student and the program by encouraging positive participation and provide feedback.

\section{4- Research problem and the challenges faced by virtual Education}

Although the effectiveness of virtual reality and its importance in the field of education and training, but it is not without drawbacks that hinder the process and use these defects and drawbacks, including as follow:

1- Limited use of virtual reality as a result of the initial high costs when buying the required hardware and the high price of the cost of production virtualization software.

2- The limited impact of the five senses in a virtual reality system that does not exceed in its use only the sense of hearing, sight and touch, but other developments in the future use of other senses 3. Excessive use of virtual reality programs and in front of computers, has a negative health impact may appear.

3- The use of special types of computer systems, which include the frequency of which more than fifteen frames per second leads to the injury of the individual nausea, headache and other symptoms such as fatigue, nervous system for animation frames and tension.

4- Virtual world puts everyone in front of the entire world allowing him all the ideas and doctrines, and this is more than the disintegration of the social and educational role, and reduces guardianship practices, and dislocate the idea of a single opinion.

- Time limits are the third millennium and the beginning of technological revolution and informatics era, in the period(2000-2030)

- Spatial borders are both Arab Republic of Egypt\& the popular Republic of China in all governmental, private and international universities.

\section{5- Brief History}

- The virtual reality actually appeared, and even use a lot, even before it called any of the names that we know about it today, the first appearance of this concept was in the early sixties of the twentieth century in the emulators form of Flight Simulators learn the pilots how to drive in the eighties of the twentieth century, when the armed forces began to fly ,the US and some European scientific institutions and the NASA agency of space create new systems for computer interactive generator for three-dimensional images.

- Where the American thinker Arthur C. Clarke is one of the first dreamers of virtual reality and published a book about science fiction called reality and the stars. Myron Krueger is the first who released the name of the artificial reality in 1970 called (the father of realism). As Jaron Lanier is the author of the virtual reality term after the founding of the Research Foundation VPL Research in 1989.

It used in several areas and in the military field, where the war games is an expensive process and may result in physical injuries and losses as they are prone to spy .Virtual reality uses to simulate battles and shootings. In the field of aviation has been the work of high-tech flight simulators, where he developed Furness Tom vacuum using a three-dimensional images simulated what guided the pilot during the flight.

As the summary of many years' experience of research . my master degree subject was about" the Chinese animation between national identity and industry". And then I published many researches about Chinese animation in the contemporary china reality. And I participate at many co- chinese - Egyptian conferences/Helwan university. I introduced this vision of developing Sino-Egyptian education 2030 .There is the main axes of the research plan, as follows

\section{5- The main axes of the research plan:}

5-1 The first axis: studying the definition of the multimedia in education \& the concept of virtual education:

-Multimedia Definition in education:

Multimedia is known in the field of technology education since the sixties. The word Multimedia consists of two parts (Multi) which is used in the English 
language in the sense of pluralism, and (Media) re fers to the media carrying information such as paper, audio tapes and disks and optical magnetic and laser tapes. "John Koegel" explained what (the Arab Organization for Education, Culture and science) pointed to that it integrates more than one way complement each other in displaying or teaching. Multimedia is a term used to describe Union software \&hardware devices that enable the user to handle benefit from: the written text, graphics, slides, audio, static image, animation, sound effects and video, aimed at achieve efficiency in the process of teaching and learning . When adding interactive to the project become an Interactive Multimedia Hypermedia, and when you add roaming the way within the project becomes a project for Hypermedia.

Multimedia technology could be given Consideration from three main angles are: (Delivery Media), (Presentation Models), and (Sensory Media): modern technology based on the nature of the learner as a human being with multi-sensory. This means that the Interactive multi-media allow the user to receive data $\&$ information and active participation in the presentation of their content that means they are Two- communication Way.

- The concept of virtual education

The word (Virtual) from Latin (Virtus), which means force or energy initial pushing. The word (Vis) means power and (Vir) means human close to him (La virtus) . This is the first reason for their impact, but also continuing presence in effect, then it isn't illusory and exist by force. Virtual is limited by reality up to (Levy, 1997).

5-2 The second axis: The impact of the difference between virtual education and training on developing the education process.

\section{6- What is the difference between virtual educa- tion and training?}

\section{1-Virtual Learning}

Virtual education is the process of teaching and learning based on the principles of effective pedagogy that means the student must take responsibility for the permanent subscription and effective. students and university professor will not meet personally, although this can happen in the virtual space, and the possibility of simultaneous interaction or asynchronous, for example, they can speak with each other in real time using the Internet, or by e-mail and partic- ipation mailing groups where (asynchronous) software techniques that don't require participants to be online at the same time.

\section{2- Virtual Training}

Virtual Learning is the default remote training using modern means of communication. It is known as a learning environment where university professor and students are being separated time or place, or both, and university professor interacts with the students to provide classroom content through administrative applications, multiple, Internet media sources, video conferencing, ... etc. Students receive the content and communicate with the teacher via the same techniques. Dubois, and Phillip say that: "The trainer who trained electronically is a real learner but learns in an electronic environment" (Dubois, and Phillip, 1998, p.137), and confirms this fact, Richard Lewis when he wonders about the nature of the exact meaning of the word (Virtual), As he think.

it means something isn't real, but the training is using electronic techniques - as Lewis said - isn't real ?! (Lewis, 1997). We should look at the results and do not look at the lack of appearance of this type of learning, there is no doubt that the results of this training suggest the existence of a real education may keep pace with the usual training.

The third axis: study of samples of virtual training tools

\section{-Virtual Training Tools}

Virtual training tools are all modern means of communication such as the computer connected to the Internet, interactive Visual Radio (TV) device, portable (Palm) and portable (WAP). These tools will be one of the most important channels for interactive and the transition training which appears in the E-training and E-training using mobile devices which called (Mobile learning).

The fourth axis: displaying the consist of virtual reality technology components:

As virtual reality technology consists of two basic components. They are software $\&$ hardware and tools system:

- Virtual reality technology components: 
A. software system: They are of two types:

1-Software System: It is an advanced computer software applications, had the ability to generate stereoscopic images at the same time in which the teacher interacts with education program. It also allows the identification of surround sound and smell in some cases, because these programs make up the virtual reality environment and aims to create it closer to the real environment, they are not programmed in a fixed predetermined path, but it is working on creating changing positions constantly, depending on the desire of the user and his actions during his interaction with it, as he is wandered in the stereoscopic environment generated by the computer.

2-Education programs: the educational materials that are designed and developed for use in the virtual reality environment to teach specific goals in languages or math or science etc.

\section{B- Hardware and tools system:}

It's devices that the teacher used it to interact with the program, and give him the sense of virtual reality,AS :Head Mounted Device(HMD),Data-Gloves,Motion Sensing.

1. Head Mounted Device(HMD): a device that is placed on the Head Device, and consists of two small video screen, the one area of it $1 \mathrm{~cm}$, placed a short distance in front of the eyes, and sometimes in each device, there is thumbnail view, to display a clear picture, we can see holograms, and it expands the field of vision without having to use complex and expensive convex lenses to provide this field as we can track impact tracking, and moving the head quickly to discover the trend.

2. Data-Gloves (Motion Sensors): They are hand gloves, commonly used in sensation or touch, allowing users to interact with the visual hologram virtual reality environment, touching stuff picked up and moved it and circulation, sensation with its hardness or smoothness when moving his fingers inside the glove.

3. Motion Sensing (Tactile gloves): which is mean- ing the sense of movement where certain parts of the human body such as the wrist, foot, knee is reached by computer in the form of white points, and there is video advice works to detect the movement of these points by the program.

And there is other virtual reality devices and tools which are used in the education process, like:multidirections telescope (boom), the automatic virtual environment cave, assistive devices, the computer system nano manipulator device or nanometer processor (Nano manipulator (,virtual worlds, for example (second life world).

Fifth axis: THE INTEGRATION OF THE Types of virtual reality environment:

-Types of virtual reality environment:

1-Virtual reality creates a state of completed presence:

It is convince the user that there is no computer and the real world, as he do not see or feel anything but only this manufacture world, which is made by computer, and acting - inside it - freely. And the vision of this world could be seen by a special helmet, or electronic glasses connected to the computer; As the user wears, in his hands electronic gloves, as an additional mean to embody the virtual reality, and allow him touching things which he (thinks) they are existed.

2-Virtual reality is limited both function \& Location: This system is used in the (Simulators), simulation devices and focus the attention of the designer, in this type to simulate the properties of certain molecules actually live (in the reality), such as the influence of gravity, or severe speed, with less attention to detail.

\section{3-Terminal Virtual Reality:}

There is the vision of the virtual world, and dealing with it, via automated computer screen, without feeling the presence of the real inside virtual world. There is who predicates with a fourth type of virtual realism, didn't exist yet, but it is used frequently in the ideas of literature of science fiction, and it is exceeded to address the senses to address the mind directly. That means if the mind receives from our different senses its sense of the world, via electrical signals, and the cognition process is the responsibility- 
of the mind, which translates these signals into elements of us by experience. So it is possible to suggest the existence of any influential by generating the same electrical signal which this influential was generated. The references differ in the naming of virtual environments and agreed in meaning and content.

Virtual Reality patterns:

1- Pre-advanced Virtual Reality: most of the virtual reality characteristics are available in it with a low degree, but the necessary of hardware and software for this type are few in number and simple in terms of complexity and development compared to their counterpart in the two coming modes.

2- Semi Advanced Virtual Reality: most of the virtual reality characteristics is available in it with a medium degree, and requires devices more and more advanced programs than those used in the previous pattern.

3- Advanced Virtual Reality :Most of the virtual reality characteristics are available in it with a high degree, but it requires special equipment and many, as well as advanced and complex programs.

Sixth axis: THE classification OF the virtual reality environment

Some of them classed the virtual reality environment to three environments, As they are classified to three environments:

\section{1-Non Immersion Virtual Reality:}

One of the most common types used because the lack of cost and this type depends on the computer and the user co-uses the traditional methods known here, such as the keyboard and mouse and joy stick throughUsing a three-dimensional interaction devices such as the glove or space ball and here the user feels the sense of co- immersion within the low default environment.

\section{2-Semi -Immersion Virtual Reality :}

The number of participants in one room are brung and watch the display on a large screen with curves in each direction and interaction. And it occurred with the virtual environment via a participant and the rest of the participants are negative observers and he is walking via the mouse and the keyboard . this type of virtual reality is characterized that it provides a sense of deep feeling with medium degree and the quality of the image is high as well as allowing the display for many viewers, but what maligned him that the role of participants is limited to watch only (such as the Planetarium).

\section{3- Immersion Virtual Reality:}

This type offers experience directly through the participant's interaction with the virtual environment and this achieved via wearing a helmet equipped with dual lens placed on the eyes and here the participant feels that he exists in the virtual environment where he senses completely with deep feelings and maligned it because its high cost and low image resolution compared to the two previous species.

Seventh: The properties of Virtual reality environment:

-Virtual reality environment properties:

In the spot of the above definition, it can identify the most important of the following characteristics that distinguish virtual reality:

1 - It is a new advanced style of education technology and integrated information, consisting of computer hardware and software.

2- It provides for the learner a safe and imaginative stereoscopic environment, and an electronic manufacture as the reality alternative. It accurately simulates the events or processes or systems of certain of it, and contain stereoscopic drawings for scenes views and sensitive effects, compacted and manufacture artificial which deceived the user that it's just fact.

3- This environment is under learner rule who sailed , dived in it, and participates an active positive participation, and not only as an external observer, so he could move things, drive it and dispose them as acting in real situations, and in the real framework of time, any action and reaction of each movement or action taken a moment, as it actually happens In the reality

4- The learner controls in this environment, interacts with them by computer using special external means of improving the movement of the teacher and connected his senses to the computer, such as goggles 
stereoscopic vision glasses (VR GLASSES) ,electronic gloves, helmets ,and joy sticks.

The Standards of good virtual reality environment:

Abdul Hamid (2003) Said that we really live in an imaginary world, many events around us are imaginary. Cinema, theater, drama and databases, even mental images composed in the memory, been also imaginary, but we don't consider all of that imaginary virtual reality environments, because virtual reality environments should be provided by the following characteristics \& considerations:

1- Honestly simulated: where you must represent and simulate the real virtual reality environment actually honest representation \& simulation.

2- Interactive Immersion \& integration. As the teacher doesn't interact with the virtual reality from the outside, but he indulges in it and become integrated and completed part of it.

3- The embodiment of personal Avatar: it is an animated puppet generated by computer, represented the user inside the virtual reality environment, and embodies the idea in the user person.

4-The disappearance of the interaction interface within the environment: because the user doesn't interact with the environment from the outside, but he is an integrated part of it, so there is no need for him to the external interaction interface, where it disappears within the environment itself, so that the user interacts directly with the virtual reality in the moment.

The eighth: the features of virtual reality system:

There are many general characteristics that combine virtual reality systems, which can't be renamed anything on behalf of the virtual world without it applies to all of these conditions:

\section{1- Immersion:}

Immersion is used in the generator virtual reality environment (Synthetic environment) acted the reality by three-dimensional stereoscopic scenes representation which affected the sense of depth and surrounded space and sensory immersion in a virtual environment is a very important part of the virtual reality. Through this feature the system isolates the audio and video user's senses from the surround world and puts instead them sensations derived from the computer. The body moves through artificial space using feedback gloves or Joystick. The sense of immersion (the feeling that completely surrounded) is given to the user is one of the main goals of the designers of virtual reality systems.

\section{2- Interaction:}

It is the imagination of any kind of realism in the interaction with any electronic representation. However, when cleans the desktop in the Windows operating system, you could see the Recycle Bin on the computer screen is not fit, but we deal with it as if it is hypothetically surface of the office as well as any icon is a representation of a program, but we use it as if it were a real entity. These are all forms of realism to interact with them in the same way we interact with cartoons and images we see it on television. The virtual Recycle Bin doesn't need any optical illusions to become a virtual. The issue is in our ability to imagine. The Recycle Bin could become real in the context of our interaction with the work. As the realistic trash in this world woven from our relation of a perception. It exists as far as we interact with them.

\section{3- Efficiency- \\ Inefficiency (Activity -Passivity):}

Virtualization can reduce Passivity symptoms that may be affected on you and the elements of the environment and the things around us to respond. It may not be according to our prejudice. And so the virtual reality systems responses must be.

\section{4- Simulation:}

Computer Graphics Applications have a great degree of realism that gives us clear pictures and animated it to life in its own way. These systems give us at the present time not only to approximate imagine of visuals' form but to portray them almost to animate life with its visual instruction and light radiation attracts the eye inside the great details of the surface. The landscapes, which produced by the lowest ability of computers today are worlds with detailed realistic photos.and the Realism simulation is not just intended images or models that mimic simulated reality significantly, but also those that allow the natural human behavior such as vision, walking and even flying within these programs.

\section{5- Synthetic Artificiality}

Some designers boast with Genuine Simulator that "the artificial thing simulates completely the authetn) 
tic. And this issue should be reconsidered. There is no flaw to be the virtual reality worlds artificial, yet they are used in order to bring benefit and happiness to its users. Synthetic Artificiality that distinguishes virtual reality is its way for excellence. We imagine when the day - where we can completely simulate everything perfectly - has come, the artist tone and the camera will return ,and the designers will start to find solutions to keep them away from this incident that killed creativity sometimes.

The Ninth: the simulation of virtual education experiments and environments via systems, programs or even applications as virtual classroom/lectures and virtual school/university.

We can simulate virtual education experiments and environments via systems, programs or even applications as follows:

Virtual educational games, Virtual theater, Virtual lab, Virtual museum ,Virtual educational environments (Virtual classrooms, training rooms, and science workshops, libraries, virtual universities, and scientific conferences),Virtual garden, Virtual space and aviation, Virtual factory and Virtual vocational training institutes, Virtual Courts \& virtual crimes, Virtual medical operations

\section{1- Virtual Classroom/lecture}

Virtual Classroom are the tools, techniques, and software on the World Wide Web "Internet" enables the teacher to disseminate lessons and objectives and put duties and tasks of study and communicate with his students via multiple technologies, as it enables the student to read goals and tutorials and solving homework and sending tasks and participation in the discussion areas and dialogue and see his progress in studying and his degree obtained. “

\section{2- Virtual School/University}

Virtual school/university is a school /university that provides students from the kids garden stage up to third secondary grade with education deliberated on the Internet with its simultaneous technology as (chat), video conferencing, electronic board, and its none simultaneous -asynchronous- technology such as email, web pages, and file transfer protocol, and newsgroups, lists or forums mailing and others, to distribute education so where students can take it from anywhere, at any time, in any way, and any speed. It can be defined procedurally as: popular school such as traditional school in the presence of teachers, students and administrative \& educational corps, but on the World Wide Web (Internet) where it isn't bound by time or place, and based on multiple global Web technologies, like: discussion ,conferences and forums, and reading lessons, and perform the duties .. , and etc.

The tenth axis: the models of virtual school/university on the world wide web (internet)

The models of these schools on the World Wide Web (Internet) are the following models:

1- Tunisian Virtual School (www.evt.edunet Tunisian virtual school introduced three schools. they are (schools offering support and escort -school teaching Arabic language to the children of expatriates- and school integration of information and communication technologies in education), and these schools are still at the beginning, but it has a good awareness to introduce a virtual school form.

For example: The support and associated school helps the pupil in the collection process and absorption, as the school provides support and accompaniment - in parallel with education - lessons related to other learning materials and levels. And it includes lessons to students of basic education: Arabic language, foreign languages, mathematics, scientific materials, technical, this will be by the adoption of interactive and collaborative activities, and the activities of creativity and invention used electronic encyclopedias, and legends, interactive exercises and educational games in the individual framework and group projects and activities of communication.

\section{6- The research results and recommendations:}

virtual reality can provide tools to increase student participation and the school/university activities can use virtual reality tools for self-learning projects and group discussions and tours the ground and the perception of the concept as the virtual reality allows natural interaction with information, instead of reading about places no learner can be seen by the virtual reality can learners discover new worlds where virtual reality can provide an educational experience finds a lot of exciting students, giving them the opportunity or motivation to learn, and confirms Sherry Aazlnger also that virtual reality can offer the necessary to visualize the tools and the formation of abstract information as it is in the framework is easy to understand, and in addition to the above, the advantages of virtual 
reality, and what distinguishes virtual reality when applied in the field of university education and an excellent means of learning and make it a number of things, including the following:

1- The learner can explore real things without compromising the standards of sizes and dimensions and time.

2- It offers an attractive education with fun and entertainment and experience the information.

3 - The possibility of the learner's interaction with the experience that he wants to learn directly.

4- It enriches the educational process with expertise and technological capabilities and modern. Training of learners to acquire technical skills and things that are difficult to train them in reality.

5- Submission of a virtual environment to sail through a three-dimensional space.

6- It enhances holograms sensory management depth and dimensions of the vacuum

7- The virtual environment checks the safety of her employer when studying serious information or difficult to obtain time and place.

8- It enables the learner to move within time and displays the positions of the past decade or speed up display future.

9- Help the learner to achieve the desired level has high precision skill.

10 - Teacher interaction with virtual reality equals or exceeds what can be achieved real reality.

First: The illustration diagrams:

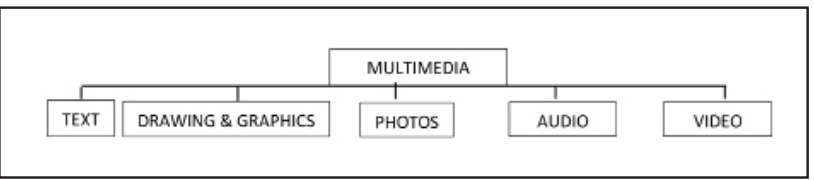

Shape (1) A graph of the constituent elements of the term multimedia
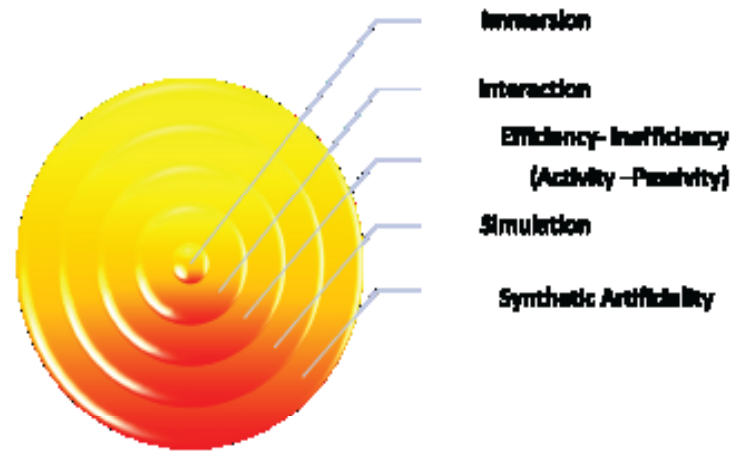

Shape (2)The Features of Virtual Reality System

\section{Second: The tools of virtual education}

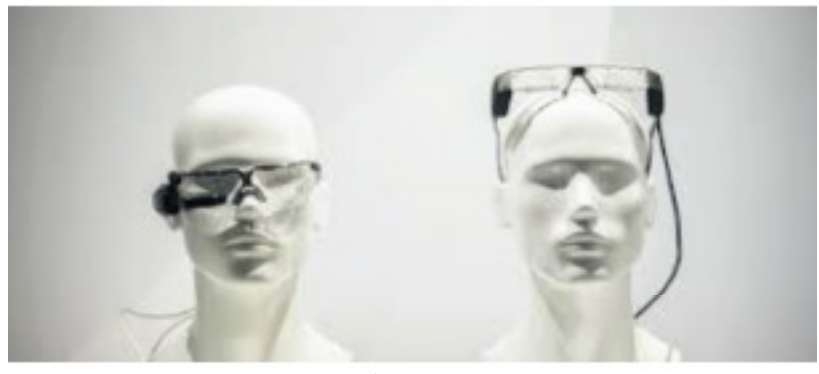

Shape (3)

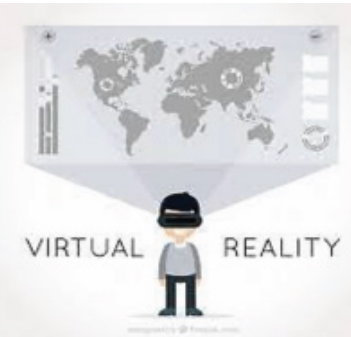

Shape (4)

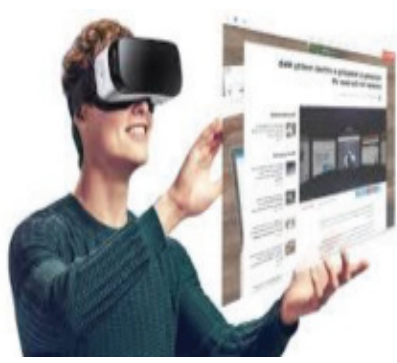

Shape (5)
Third: The integration of virtual education process

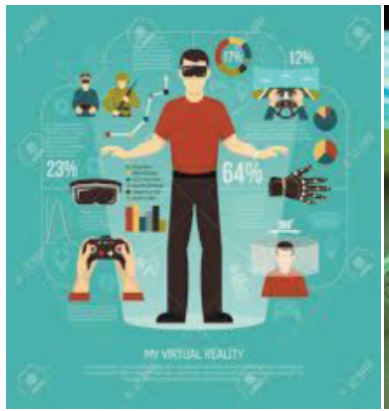

Shape (6)

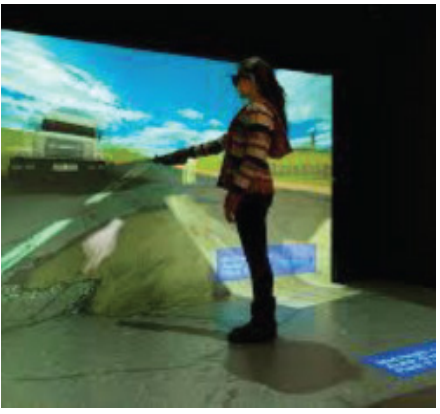

Shape (7)
Forth: The uses of virtual reality in the education process

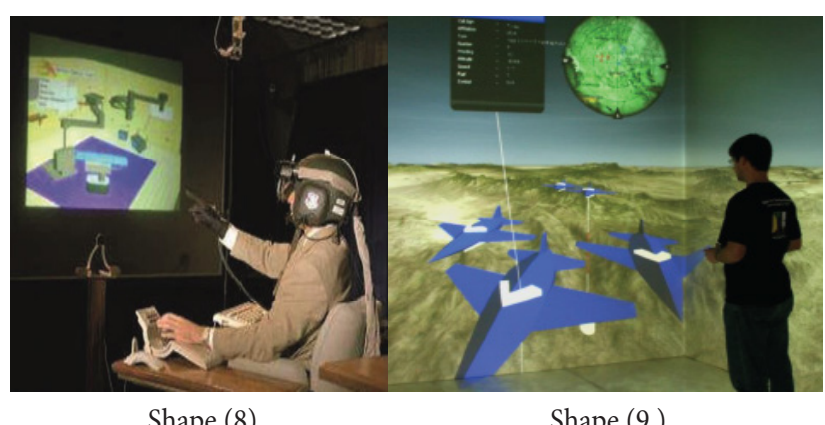

Fifth: The uses of Multimedia in animation to develop the vision Of Sino-Egyptian Education (2030) 

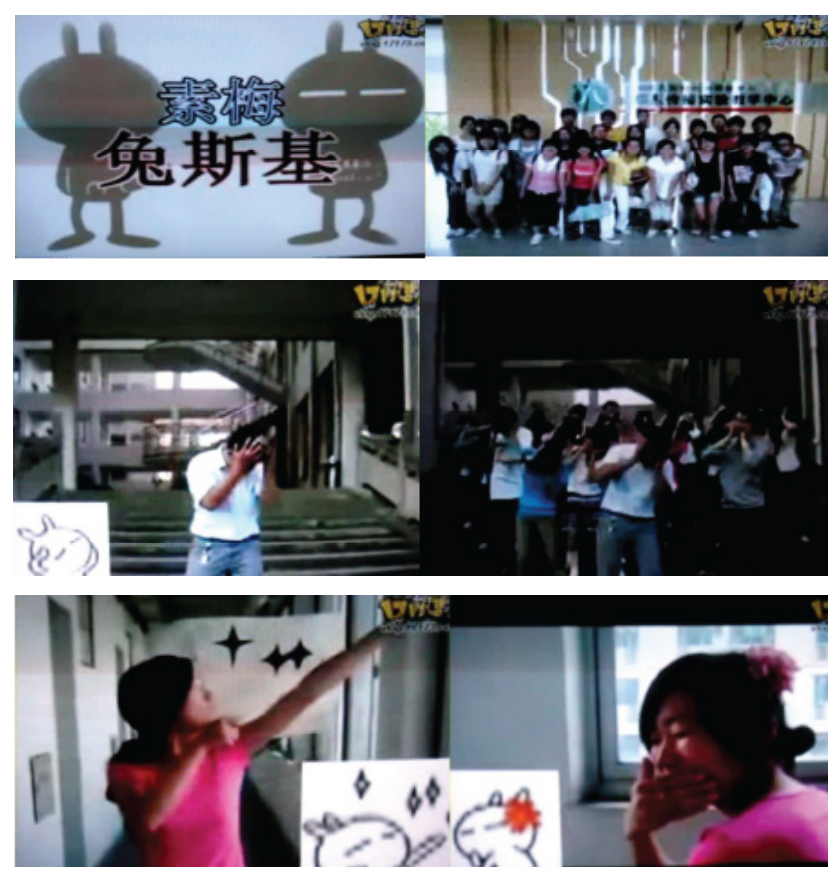

Shape (10) The role of animation to develop the universities, colledges, and training centers

Sixth: The role of publishing for animation in the media to develop the vision Of Sino-Egyptian Education (2030)

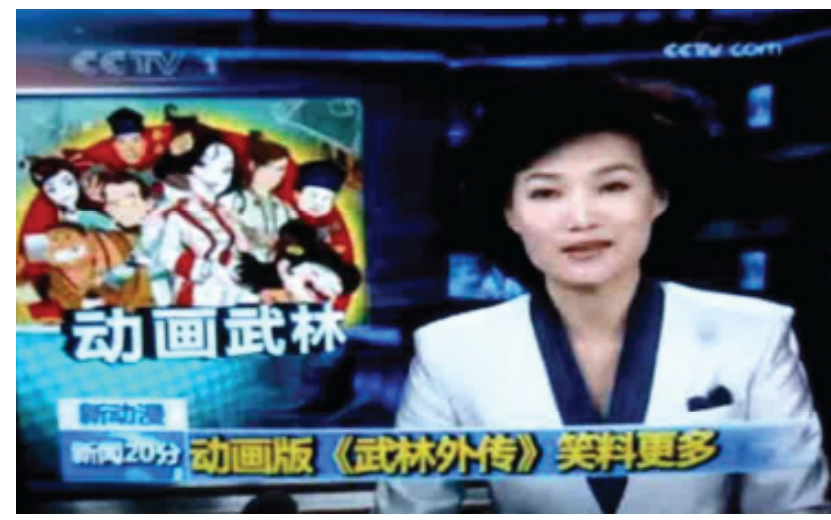

Shape (11) Publishing promo Chinese news of Chinese animation film during displaying it

in cinema in china on cctv channels

\section{7-The research results and recommendations:}

virtual reality can provide tools to increase student participation and the school/university activities can use virtual reality tools for self-learning projects and group discussions and tours the ground and the perception of the concept as the virtual reality allows natural interaction with information, instead of reading about places no learner can be seen by the virtual reality can learners discover new worlds where virtual reality can provide an educational experience finds a lot of exciting students, giving them the opportunity or motivation to learn, and confirms Sherry Aazlnger also that virtual reality can offer the necessary to visualize the tools and the formation of abstract information as it is in the framework is easy to understand, and in addition to the above, the advantages of virtual reality, and what distinguishes virtual reality when applied in the field of university education and an excellent means of learning and make it a number of things, including the following:

1 - The learner can explore real things without compromising the standards of sizes and dimensions and time.

2- It offers an attractive education with fun and entertainment and experience the information.

3- The possibility of the learner's interaction with the experience that he wants to learn directly.

4- It enrich the educational process with expertise and technological capabilities and modern. Training of learners to acquire technical skills and things that are difficult to train them in reality.

5- Submission of a virtual environment to sail through a three-dimensional space.

6- It enhances holograms sensory management depth and dimensions of the vacuum

7- The virtual environment checks the safety of her employer when studying serious information or difficult to obtain time and place.

8- It enables the learner to move within time and displays the positions of the past decade or speed up display future.

9- Help the learner to achieve the desired level has high precision skill.

10- Teacher interaction with virtual reality equals or exceeds what can be achieved real reality

\section{8- Conclusion}

The Sino- Egyptian education vision is developed the labor market Participation in skills' development and vocational \& artificial \& technical training of the mechanisms of Chinese animation industry with specialized educational institutions:there are training courses for students at universities, academic training and education centers in universities in China to get a university degree in animation and provide job opportunities and training seminars for teachers of computer graphics and researchers. As china builds the largest nursery for engineers and scientific researchers in the world. This vision should be developed by using virtual education which depended on both e- 
training \& e-learning

Finally, this research ended by exploring the new contemporary vision Sino-Egyptianeducation for the next ten years of the decade (2020-2030) via the electronic publishing for animation Chinese \& Egyptian and multimedia role in virtual education and training . At the end the research's results \& recommendations, introducing experiments in which could be progressed this education process in china \& Egypt(2030).

\section{9-References}

\section{-Arabic References:}

1. El-husary, Ahmed (2000): the Education Technology in reality and hope school system, the Seventh Annual Scientific Conference of the Egyptian assosciate for Education Technology, fulfillment house , Mansoura.

2. El-garib, Zaher Ismail (2001): Information technology and modernization of education, the world of the book ,Cairo.

3. El-Mousa, Abdullah Abdul-Aziz and Al-Mubarak, Ahmed Abdulaziz (2005): E-learning principles and application, Data Network Foundation, Riyad

4. El-Sharhan, Gamal (2006): E-book and e-school and virtual teacher, print2, Riyadh

5. Mhaisni Ibrahim ,Hashem, and Khadija bent Hussein (1423) E-school is the Future School", a study of concepts and models" worksheet submitted to the School of the Future Symposium, King Saud University, College of Education 8-16-17-1423h.

6. Mousa, Abdullah and Abdul-Aziz Al-Mubarak, Ahmed Abdulaziz (2005): E-learning principles and application, Data Network Foundation ,Riyadh.

7. EL-Arini, Abdul Rahman (1423) of programmING instruction to e-Learning, Knowledge Magazine, Issue 91 SHAWAL 1423 ,r December 2003.

\section{-Foreign References}

(1) Martin, Chuck (1999): the Internet future, translation of Moses Younis, International House ideas / El-Riyad.

(2) Levy, p (1997) quest-ce que le virtuel? Paris : la Decouverte

-Unpublished doctoral dissertation

(1) Jacobsen, Matthew, The wandering adolescent of contemporary Japanese anime and videogames,
Queen Mary University of London (UnitedKingdom),ENGLAND, unpublished Ph.D. thesis, ProQuest Dissertations Publishing, 2014. 10088506.

(2) Liu, Xueting, Perception Analysis for Manga and Anime Applications, unpublished Ph.D. thesis,Computer Science and Engineering Department, The Chinese University of Hong Kong (Hong Kong), ProQuest Dissertations Publishing, 2014. 3707446.

(3) Lee, Laura .Cinema of the interval: Stop -motion animation and Japanese film aesthetics, unpublished Ph.D. thesis ,Cinema and Media Studies Department,The University of Chicago, Illinois -United States ,ProQuest Dissertations Publishing, 2010. 3419663.

\section{-Unpublished master's thesis}

(1) Dina Ali Mohammed El-Besomey, Chinese Animation between national identity and industry, non-published master thesis in animation department/ Fine Arts Faculty / minia university, 2012.

(2) Liu, Cheng .Developing Chinese artistic elements in sci-fi animation environment design, Unpublished master thesis ,Peking University. (People's Republic of China), ProQuest Dissertations Publishing, 2010. 10437520 .

(3) Li, Ying .The research on the molding of Chinese three-dimensional animation roles, Unpublished master thesis, Shanghai University (People's Republic of China), ProQuest Dissertations Publishing,

(4) Marwa Ahmed Yousef Al-Sharif, animation employment and multimedia technology in the production of an entertaining educational site, unpublished Master Thesis, 2011.

(5) Ma, Qian .A study on Chinese comic fan's sensation difference about the sino- Japanese animation, unpublished master thesis, Central South University (People's Republic of China), ProQuest Dissertations Publishing, 2010. 10445381.

(6) Sun, jia, research on dougong generation in computer aided automatic generation of Chinese ancient architecture animation, unpublished master thesis(m.a.) ,Beijing university of technology (people's republic of China), ProQuest Dissertations Publishing, 2009. H216615.

(7) Ye, Hong Pian .A Study on the Type of Character Images in Chinese Animation, unpublished master thesis (M.A.) ,Shanghai University (People's Republic of China), ProQuest Dissertations Publishing, 2007. H317722. 


\section{-Published researches}

(1) Dina Ali Mohammed El-Besomey, Chinese Animation between national identity and industry, published worksheet of master thesis brief in the Journal, which released Quarterly Periodical Refereed by Chinese - Egyptian center/Helwan University :about 2nd international Chinese Egyptian conference, in collaboration with NANKAI university, china future of Egyptian- Chinese, and Arab- Chinese relations in 21 st century / Helwan university, (17th-18th of march, 2013).

(2) Dina Ali Mohammed El-Besomey, The impact of education \& media technology on Chinese animation industry, published research in the Journal, which released Quarterly Periodical Refereed by Chinese - Egyptian center/Helwan University :about 2nd international Chinese Egyptian conference, in collaboration with NANKAI university, china future of Egyptian- Chinese, and Arab- Chinese relations in 21 st century / Helwan university, (17th-18th of march, 2013).

(3) Dina Ali Mohammed El-Besomey, Chinese Animation between Economic And Politic, published research in the Journal, which released Quarterly Periodical Refereed by Chinese - Egyptian center,about 3rd international Chinese Egyptian conference / Helwan university, 2014.

\section{- Stand-alone Web document}

1-www.ergo-eg.com/ppt/2vra.pdf

2-http://technologyame.weebly.com

3-www.achrd.com/forums/index.php?act=Attach\&type $=$ post\&id $=9$

4-http://rf1 02010.blogspot.com/2011/05/blog-

5-http://vr-tec.blogspot.com.eg/2014/04/2.

html\#!/2014/04/2.html

6-http://fathkg.forumegypt.net/t15-topic 